Volume 8

Issue 4 - Cancer Screening

Article 10

10-18-2021

\title{
A Novel Code Team Leader Card to Improve Leader Identification
}

Palak Shah

Vinod Havalad

Follow this and additional works at: https://aah.org/jpcrr

Part of the Cardiovascular Diseases Commons, Critical Care Commons, Medical Education Commons, Patient Safety Commons, and the Pediatrics Commons

\section{Recommended Citation}

Shah P, Havalad V. A novel Code Team Leader Card to improve leader identification. J Patient Cent Res Rev. 2021;8:354-9. doi: 10.17294/2330-0698.1847

Published quarterly by Midwest-based health system Advocate Aurora Health and indexed in PubMed Central, the Journal of Patient-Centered Research and Reviews (JPCRR) is an open access, peer-reviewed medical journal focused on disseminating scholarly works devoted to improving patient-centered care practices, health outcomes, and the patient experience. 


\title{
A Novel Code Team Leader Card to Improve Leader Identification
}

\author{
Palak Shah, DO, ${ }^{1}$ Vinod Havalad, MD ${ }^{2}$ \\ ${ }^{1}$ Pediatric Critical Care Medicine, Presbyterian Hospital - The Children's Center at Presbyterian, Albuquerque, NM; \\ ${ }^{2}$ Pediatric Simulation Program, Pediatric Critical Care Medicine, Advocate Children's Hospital, Advocate Aurora \\ Health, Park Ridge, IL
}

\begin{abstract}
Prompt and clear code team leader identification is vital in effective cardiopulmonary resuscitation (CPR), and pediatric trainees often have limited experience in these scenarios. This project sought to develop a tangible object that provided clear leader identification and assisted in code team management and simulated team training. A Code Team Leader Card (CTLC) was designed to provide clear leader identification while simultaneously providing a cognitive aid via integration of pediatric advanced life support (PALS) algorithms. Additionally, CTLC served to occupy the leader's hands to limit their ability to intervene on procedural tasks. The CTLC was incorporated into pediatric resident simulation training, and pre- and postintervention survey data were analyzed. Analysis particularly focused on whether "a leader was clearly identified by all team members." The relationship between CTLC implementation and consistent leader recognition was evaluated using chi-squared test, and secondary qualitative data were obtained via debriefing sessions.

Pediatric residents completed 131 surveys prior to CTLC implementation and 41 surveys after implementation. Consistent code team leader recognition increased significantly from $61.8 \%$ (81 of 131) pre-CTLC to $80.5 \%$ (33 of 41) after introduction of CTLC ( $P=0.027$ ). Participants commented on the benefits of CTLC during debriefing sessions. Use of a CTLC significantly improved leader recognition during simulated CPR. Inclusion of PALS algorithms led to normalization and increased utilization of these adjunct materials. The CTLC provided a secondary benefit of occupying the leader's hands, thereby allowing that person to focus on overseeing the team rather than assisting with procedural tasks. (J Patient Cent Res Rev. 2021;8:354-359.)
\end{abstract}

Keywords simulation; resuscitation; medical education; code team; leader identification; pediatric training

$\mathrm{S}$ uccessful cardiopulmonary resuscitation (CPR) requires effective teamwork and communication among multiple health care professionals in a highly stressful environment. ${ }^{1-3}$ Learning and practicing effective teamwork and communication requires clearly identified team member roles, especially the role of code team leader. ${ }^{4,5}$

During an acute resuscitation, the code team relies on a leader to maintain situational awareness and facilitate resuscitative measures in a timely manner. This is especially true when code team size is reduced during times of restricted patient exposure, such as during the

Corresponding author: Palak Shah,

Pediatric Critical Care Medicine, Presbyterian Hospital, 1100 Central Avenue SE, Albuquerque, NM 87106

(Palak1289@gmail.com)
COVID-19 pandemic. The literature demonstrates that human factors such as teamwork and leadership have a direct effect on adherence to resuscitation algorithms and the outcome of CPR. ${ }^{6}$ Yet, this leadership responsibility can be difficult, as labor and tasks are often fragmented by team member job specifications. ${ }^{7}$ A leader's task is further complicated by varying levels of training and experience within the team itself. ${ }^{8-11}$ Thus, a code team leader should primarily focus on team management rather than interventional skills during a resuscitation attempt, regardless of neonatal, pediatric, or adult situations.

Code team leaders who embrace their position tend to have more effective leadership, better team coordination, and overall superior performance. ${ }^{12,13}$ The leader's ability to quickly build a structured environment leads to enhanced cooperation between team members and CPR processes ${ }^{3,13}$ and significantly improves adherence to evidence-based algorithms. ${ }^{9,14}$ The literature also demonstrates that prompt leader identification contributes 
to improved communication, timeliness of interventions, and overall effectiveness of the CPR, $, 1,4,8,12,15$ while ineffective identification causes communication errors and delays in intervention. ${ }^{1,13,15-17}$ Multiple studies have demonstrated that leader identification is especially important in large medical centers where resuscitations are dependent on the team members available and the numerous team members involved may have infrequent interactions with one another. ${ }^{12,18,19}$ This challenge is further magnified during a pandemic, when personal protective equipment may further obscure appropriate team member identification.

Unfortunately, methods for designating and identifying a code team leader have been difficult in both simulated and real-life CPR. A variety of solutions have been proposed and implemented with varying rates of success, including, but not limited to, strategic positioning around the patient, headwear, lanyards, signs, and vests. ${ }^{4,20}$ Although these accessory items may be successful in visually identifying the leader, health care professionals have been reluctant to use such objects as they do not provide secondary utility beyond identification alone, possibly resulting in a breakdown of the code team structure. ${ }^{4}$

In addition to the challenges of code team leader identification, successful pediatric CPR is dependent on well-trained providers. ${ }^{21}$ Approximately 16,000 pediatric patients suffer a cardiac arrest event per year nationally. ${ }^{22}$ Given this infrequent occurrence, pediatric care providers, specifically pediatric trainees, have limited experience and proficiency in successful CPR. ${ }^{23}$ These resuscitation skills may improve with increased knowledge of the appropriate guidelines and algorithms. ${ }^{24,25}$

The specific aims of this project were to 1) develop a Code Team Leader Card (CTLC) to provide clear code team leader identification and occupy the leader's hands so that this individual was able to focus on leading the team without the distraction of procedural or interventional tasks while also providing valuable resuscitative information in the form of evidence-based pediatric advanced life support (PALS) algorithms, and 2) evaluate the effectiveness of the CTLC in code team leader identification during simulated pediatric CPR.

\section{METHODS}

\section{Pediatric CPR Simulations}

Advocate Children's Hospital in Park Ridge, Illinois, is a tertiary care pediatric medical center at which the pediatric residency program is a 3-year training program and includes 12 residents per year. Each pediatric resident participates in 4 scheduled simulations per year, with an average of 2 clinical cases per simulation session to further enhance their learning and education in various clinical situations. Simulation sessions are organized and facilitated by attending physicians from pediatric critical care and hospital medicine. Clinical scenarios include, but are not limited to, sepsis, cardiac arrhythmias, electrolyte imbalances, toxicology, and respiratory disease processes.

The simulation team is composed of 4-6 pediatric residents from all years of training, nonstrategically randomized with every simulation session. Team member roles are self-appointed or assigned by the code team leader, depending on the individual group, and the responsibilities tend to rotate with every simulation case, exposing residents to different roles throughout their training. Each simulation ends with a debriefing session to identify strengths and areas of improvement for the team. At the end of the session, the participants are surveyed on a variety of topics related to the simulation experience.

\section{Code Team Leader Card}

The developed CTLC is a double-sided, $12 \times 18$-inch laminated card designed to be easily identifiable with its brightly colored text and a vivid orange border to provide clear code team leader identification (Figure 1). It was made large enough to occupy the leader's hands. To allow the CTLC to provide valuable evidence-based resuscitative information to increase adherence to guidelines and improve patient outcomes, the American Heart Association permitted the usage and reproduction of its three main PALS algorithms onto the CTLC. The included PALS algorithms are: 1) pediatric tachycardia with a pulse and poor perfusion, 2) pediatric bradycardia with a pulse and poor perfusion, and 3) pediatric cardiac arrest with dosing and additional detailed information. ${ }^{26}$

The CTLC cost was nominal, and no additional funding was acquired for its production. The card was kept located on the simulation resuscitation cart for quick, easy access for the code team leader during the simulated assessment and treatment of clinically decompensating patients.

We predicted the value of the PALS algorithms would be readily recognized, thus increasing the likelihood that the CTLC would be consistently used during simulation CPR and allow demonstration of its novel features as compared to accessory items described in previous publications. ${ }^{4,20}$

\section{Surveys}

The local institutional review board declared this project to be exempt. Surveys were developed by the Advocate Children's Hospital simulation physicians and researchers and validated by the institution prior to utilization. Resident survey data obtained before and after implementation of the CTLC were retrospectively 


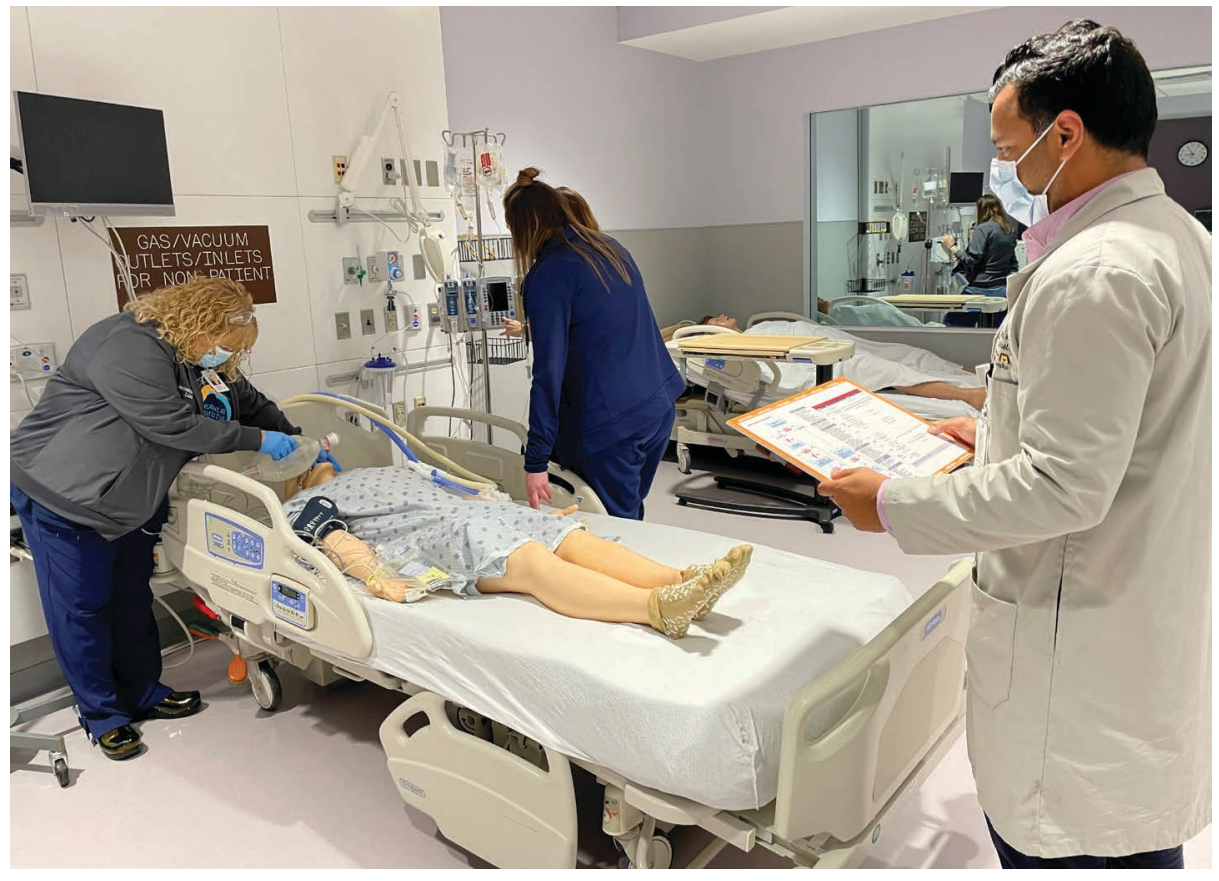

Figure 1. Photograph depicting implementation of the Code Team Leader Card during simulated acute resuscitation training. analyzed. All written surveys were voluntarily and anonymously completed without identifying factors to reduce bias in responses.

Each survey consisted of 4 questions regarding demographics and 19 questions regarding the overall simulation experience and teamwork (Online Appendix A). The demographic questions included type of provider, primary work area, type of simulation, and how many previous simulations the respondent had participated in. Each resident's year of training was not identified to ensure that the surveys were completed anonymously without the possibility of identification. Of the remaining questions, 8 multiple-choice and 3 open-ended questions focused on the general simulation experience and 8 questions focused on teamwork (Online Appendix A).

Analysis pertaining to our project focused on the specific teamwork question: "A leader was clearly recognized by all team members." This question was answered via a Likert scale consisting of the answer options "never or rarely," "inconsistently recognized," and "consistently recognized." When analyzing the data, we scored the responses using binary variables of 0 (for never/rarely or inconsistently recognized) or 1 (for consistently recognized). During debriefing sessions, secondary qualitative data regarding CTLC use were obtained.

\section{Statistical Analysis}

The relationship between CTLC implementation and consistent leader recognition was evaluated by chi- squared analysis using SPSS Statistics ${ }^{\circledR}$ software (version 21.0, IBM Corporation).

\section{RESULTS}

Prior to CTLC introduction, pediatric residents completed 131 surveys; after implementation of the CTLC, pediatric residents completed 41 surveys. Consistent code team leader recognition increased significantly from $61.8 \%(\mathrm{n}=81)$ pre-CTLC to $80.5 \%(\mathrm{n}=33)$ post-CTLC introduction $(\mathrm{P}=0.027)$ (Figure 2). Upon learning of the $61.8 \%$ baseline rate, researchers established that an improvement to greater than $75 \%$ would substantiate the intervention's impact as meaningful.

In simulation debriefing sessions, participants commented on the benefits of CTLC use. One pediatric resident stated that they "never had to worry about having the PALS card on [them] at all times or fumbling with it in front of others." Other feedback included that the CTLC "made it easy to identify the team leader right away, especially if out of the PICU" and "forced [the leader] to stay focused on [their] role as team leader and not get involved in procedural tasks." Suggested improvements included adding "more medication dosing or protocols to the card" and having the card "be part of the PICU and floor resuscitations and not just in simulated settings."

\section{DISCUSSION}

In pediatric resuscitation, prompt and accurate code team leader identification has been a long-standing obstacle to 

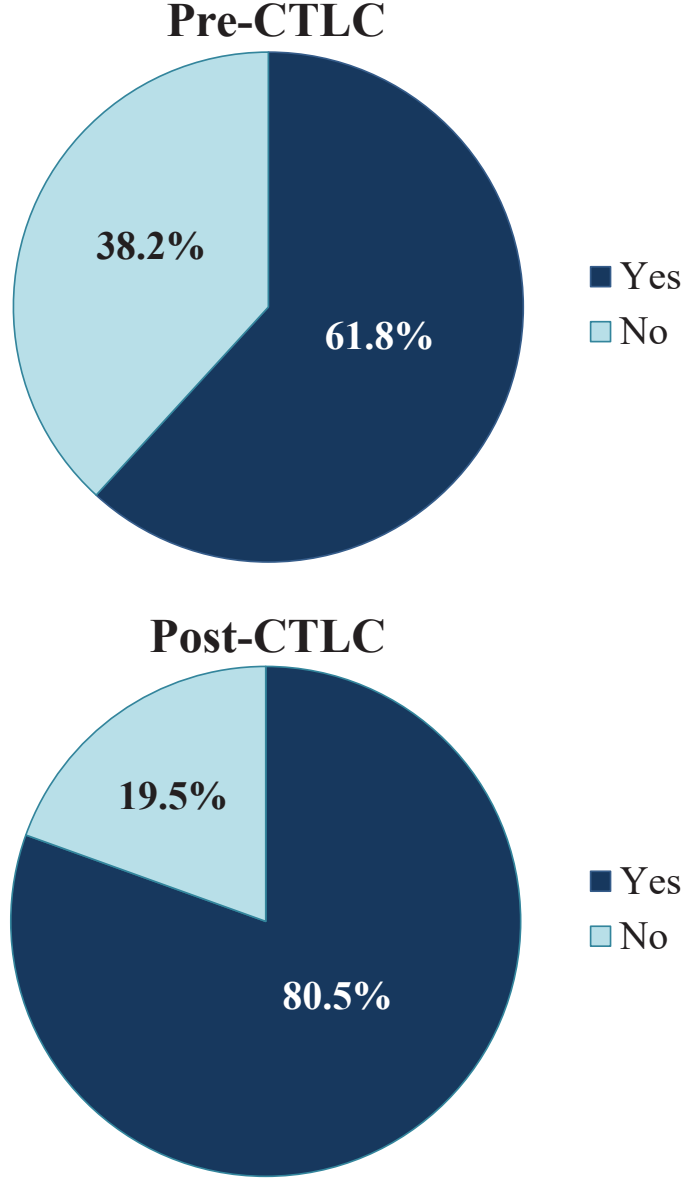

Figure 2. Comparison of successful code team leader identification pre-Code Team Leader Card (CTLC) implementation ( $n=131)$ and post-CTLC implementation $(n=41)$.

effective CPR. Reduced code team size and/or personal protective equipment usage during an acute resuscitation may further complicate timely leader identification, a circumstance more commonly encountered during the COVID-19 pandemic. This project evaluated the use and effectiveness of the CTLC as a novel innovation in addressing leader identification, discouraging the leader's active participation in resuscitative efforts (per guidelines), and providing valuable cognitive CPR aids. Our analysis demonstrated a significant improvement in leader recognition during simulated patient encounters with the use of the CTLC.

During simulation debriefing sessions, several code team leaders acknowledged that inclusion of the PALS algorithms on the CTLC led to normalization and increased utilization of these adjunct materials during CPR, which may not have occurred if leaders were to rely on their individual PALS pocket reference cards.
Although pediatric residents undergo PALS certification throughout their training, their exposure to and awareness of PALS algorithms may be limited. ${ }^{23}$ Use of the CTLC with PALS algorithms can benefit pediatric residents in knowledge retention both in simulated and real-life acute resuscitation encounters. ${ }^{24,25}$ Immediate access to essential resuscitation information can lead to swifter medical interventions, tighter adherence to CPR algorithms, and limit opportunities for error.

The CTLC also provided a secondary benefit of occupying the code team leader's hands during a CPR, thereby allowing that person to focus on overseeing the team rather than assisting with procedural tasks, an extremely beneficial aspect to this tool. ${ }^{6,13,19} \mathrm{~A}$ vital aspect of being a successful leader includes evaluating the situation in its entirety, which is difficult to accomplish if the leader is focused on fragmented tasks. ${ }^{6,13,19}$ With the use of the CTLC, leaders were able to fully concentrate on managing the code team, providing thorough and complete patient care.

\section{Limitations}

As with many new intervention techniques, this CTLC project had limiting factors. CTLC introduction occurred at a single institution and was confined to a specific pediatric residency program and its trainees. Residents underwent multiple simulations over their 3-year training and may have completed additional pre-CTLC surveys, leading to duplicate preintervention data. Post-CTLC surveys were collected for 7 months following CTLC implementation, in comparison to 2 years of pre-CTLC data, likely contributing to decreased post-CTLC survey completion and possibly impacting the final results. Initial CTLC implementation and surveying also focused on simulated situations, which can differ significantly from real-life CPR.

To yield the most accurate interpretation of the intervention, CTLC usage should be reproduced and broadened to multiple pediatric medical centers and multidisciplinary teams including, but not limited to, nursing, respiratory therapy, and pharmacy staff to allow for more robust data collection and ensure adequate participation throughout the project. Upon reproduction, the CTLC could also be adapted to include neonatal and adult CPR algorithms (after seeking the necessary approval from organizations including the American Heart Association) or include customized content to allow for more widespread implementation across various medical centers and training institutions.

Continued usage of CTLC in real-life situations is the best method to assess its effectiveness and application 
in clinical practice. Implementing the CTLC among all pediatric simulated and acute care situations will require a cultural change, which can be achieved through continued education on the benefits and success of the CTLC.

\section{CONCLUSIONS}

This project demonstrated a significant improvement in code team leader recognition during simulated patient scenarios with the use of a newly developed Code Team Leader Card. Simulation debriefing sessions revealed that inclusion of pediatric advanced life support algorithms led to normalization and increased utilization of these adjunct materials. The CTLC also occupied the holder's hands during a resuscitation, allowing the leader to focus on overseeing the team rather than assisting with procedural tasks. With ongoing efforts to enhance CPR scenarios, the CTLC is a novel innovation to address the difficult intricacies of code team leader identification, delays in intervention, and errors in communication in various medical environments, thereby possibly enhancing patient care and outcomes.

\section{Patient-Friendly Recap}

-When administering CPR in hospital settings, it is important that one person assumes the role of code team leader and that other team members quickly recognize who the leader is in the moment.

- Authors developed a laminated card, which included CPR instructions pertaining to several scenarios, for the code team leader to hold.

- In pediatric resuscitation training simulations, use of this novel Code Team Leader Card increased leader identification from $62 \%$ to $81 \%$ and helped ensure that leaders refrained from inappropriately engaging in CPR tasks.

\section{Acknowledgments}

The authors thank Lorene Schweig and Cheryl Lefaiver of Advocate Aurora Research Institute for their contributions to this project and manuscript. We also acknowledge the American Heart Association for permitting usage of the pediatric advanced life support algorithms and images for production of the Code Team Leader Card.

\section{Author Contributions}

Study design: Havalad. Data acquisition or analysis: Shah and Havalad. Manuscript drafting: Shah and Havalad. Critical revision: Shah and Havalad.

\section{Conflicts of Interest}

None.

\section{References}

1. Härgestam M, Hultin M, Brulin C, Jacobsson M. Trauma team leaders' non-verbal communication: video registration during trauma team training. Scand J Trauma Resusc Emerg Med. 2016;24:37. CrossRef

2. Sharek PJ, Parast LM, Leong K, et al. Effect of a rapid response team on hospital-wide mortality and code rates outside the ICU in a Children's Hospital. JAMA. 2007;298:2267-74. CrossRef

3. Yeung JHY, Ong GJ, Davies RP, Gao F, Perkins GD. Factors affecting team leadership skills and their relationship with quality of cardiopulmonary resuscitation. Crit Care Med. 2012;40:2617-21. CrossRef

4. Prince CR, Hines EJ, Chyou PH, Heegeman DJ. Finding the key to a better code: code team restructure to improve performance and outcomes. Clin Med Res. 2014;12:47-57. CrossRef

5. Price JW, Applegarth $\mathrm{O}, \mathrm{Vu}$ M, Price JR. Code blue emergencies: a team task analysis and educational initiative. Can Med Educ J. 2012;3:e4-20.

6. Hunziker S, Johansson AC, Tschan F, et al. Teamwork and leadership in cardiopulmonary resuscitation. $J \mathrm{Am}$ Coll Cardiol. 2011;57:2381-8. CrossRef

7. Finn R. The language of teamwork: reproducing professional divisions in the operating theatre. Hum Relat. 2008;61:103-30. CrossRef

8. Clarke S, Carolina Apesoa-Varano E, Barton J. Code Blue: methodology for a qualitative study of teamwork during simulated cardiac arrest. BMJ Open. 2016;6(1):e009259. CrossRef

9. Hunziker S, Tschan F, Semmer NK, Marsch S. Importance of leadership in cardiac arrest situations: from simulation to real life and back. Swiss Med Wkly. 2013;143:w13774. CrossRef

10. Marsch SCU, Müller C, Marquardt K, Conrad G, Tschan F, Hunziker PR. Human factors affect the quality of cardiopulmonary resuscitation in simulated cardiac arrests. Resuscitation. 2004;60:51-6. CrossRef

11. Tschan F, Semmer NK, Gautschi D, Hunziker P, Spychiger M, Marsch SU. Leading to recovery: group performance and coordinative activities in medical emergency driven groups. Hum Perform. 2006;19:277-304. CrossRef

12. Andersen PO, Jensen MK, Lippert A, Østergaard D. Identifying non-technical skills and barriers for improvement of teamwork in cardiac arrest teams. Resuscitation. 2010;81:695-702. CrossRef

13. Cooper S, Wakelam A. Leadership of resuscitation teams: 'Lighthouse Leadership.' Resuscitation. 1999;42:27-45. CrossRef

14. Hoff WS, Reilly PM, Rotondo MF, DiGiacomo JC, Schwab $\mathrm{CW}$. The importance of the command-physician in trauma resuscitation. J Trauma. 1997;43:772-7. CrossRef

15. Georgiou A, Lockey DJ. The performance and assessment of hospital trauma teams. Scand J Trauma Resusc Emerg Med. 2010;18:66. CrossRef

16. Sarcevic A, Marsic I, Waterhouse LJ, Stockwell DC, Burd RS. Leadership structures in emergency care settings: a study of two trauma centers. Int J Med Inform. 2011;80:227-38. CrossRef

17. Thomas EJ, Taggart B, Crandell S, et al. Teaching teamwork during the Neonatal Resuscitation Program: a randomized trial. J Perinatol. 2007;27:409-14. CrossRef

18. Hodgetts T, Turner L. Trauma rules 2 incorporating military trauma rules. Ann R Coll Surg Engl. 2010;92(2):180.

19. Mellick LB, Adams BD. Resuscitation team organization for emergency departments: a conceptual review and discussion. Open Emerg Med J. 2009;2:18-27. 
20. Sarcevic A, Palen LA, Burd RS. Coordinating time-critical work with role-tagging. In: CSCW 11 Conference Committee (ed). CSCW '11: Proceedings of the ACM 2011 Conference on Computer Supported Cooperative Work. ACM Press; 2011, p. 465.

21. Gonçales PD, Polessi JA, Bass LM, et al. Reduced frequency of cardiopulmonary arrests by rapid response teams. Einstein (Sao Paulo). 2012;10:442-8. CrossRef

22. Topjian AA, Berg RA, Nadkarni VM. Pediatric cardiopulmonary resuscitation: advances in science, techniques, and outcomes. Pediatrics. 2008;122:1086-98. CrossRef

23. Mickelsen S, McNeil R, Parikh P, Persoff J. Reduced resident "code blue" experience in the era of quality improvement: new challenges in physician training. Acad Med. 2011;86:726-30. $\underline{\text { CrossRef }}$
24. Brown TB, Dias JA, Saini D, et al. Relationship between knowledge of cardiopulmonary resuscitation guidelines and performance. Resuscitation. 2006;69:253-61. CrossRef

25. Knight LJ, Gabhart JM, Earnest KS, Leong KM, Anglemyer A, Franzon D. Improving code team performance and survival outcomes: implementation of pediatric resuscitation team training. Crit Care Med. 2014;42:243-51. CrossRef

26. Topjian AA, Raymond TT, Atkins D, et al. Part 4: Pediatric Basic and Advanced Life Support: 2020 American Heart Association guidelines for cardiopulmonary resuscitation and emergency cardiovascular care. Circulation. 2020;142(16 suppl 2):S469-523. CrossRef

(C) 2021 Advocate Aurora Health, Inc. 